\title{
Guidelines for Authors
}

Fontanus is an annual publication devoted to scholarly research based principally upon McGill University collections. The term 'collections' is interpreted in the broadest sense, to include books, archives, specimens, artifacts, buildings and other forms of documentary evidence. Contributions derived from all aspects of McGill collections will be considered. Submission of a contribution is understood to imply that no paper containing essentially the same material has been published previously and that the manuscript is not under editorial consideration elsewhere. All submissions will be reviewed by members of the Editorial Board and refereed by experts in the appropriate field. Any substantial changes will be cleared with the author before publication. Send submissions, prepared according to the instructions below, to:

Dr. Hans Möller
Editor
FONTANUS
McLennan Library Building
3459 McTavish Street
Montreal, Quebec, H3A 1Y1
phone: (514) $398-4740$
fax: $\quad$ (514) 398-7356

\section{Form of Manuscript}

All manuscripts (in two copies) must be typewritten and double-spaced. Articles may also be submitted on computer disk, using WordPerfect $4.2,5.0$ or 5.1 software. Notes should be numbered consecutively and follow the text of the article. Author's name should appear after the title and before the text of the article. A short biographical note of no more than 100 words should be included. Degrees, current and previous positions and major publications should be listed.

\section{Abstracts}

A brief abstract (of no more than 200 words) of the content of the article should be prepared by the author.

\section{Form of Citation}

Manuscripts should conform to the standards outlined in The Canadian Style: a guide to writing and editing (by the Department of the Secretary of State of Canada) Toronto, London: Dundurn, 1985. Translation of passages in other than French or English should be provided in the text.

\section{Illustrations}

Photocopies of visual material (with brief captions) must be submitted by authors for initial evaluation. Once an article has been accepted, the author is responsible for supplying clear black and white glossy photos and for securing the permission to publish copyright material if necessary.

Fontanus is published each calendar year. Articles submitted before December 15 are eligible for consideration for the following year's issue. Authors will have the opportunity to review their manuscripts after editing has been completed. 